\title{
Does multimedia support individual differences? - EFL learners' listening comprehension and cognitive load
}

\author{
Hui-Yu Yang \\ Fujian University of Technology, China
}

\begin{abstract}
The present study examines how display model, English proficiency and cognitive preference affect English as a Foreign Language (EFL) learners' listening comprehension of authentic videos and cognitive load degree. EFL learners were randomly assigned to one of two groups. The control group received single coding and the experimental group received dual coding. The results show that the display model affects EFL learners' cognitive load and listening comprehension of CNN news. There is no interaction among English proficiency, cognitive preference and experimental conditions on the listening comprehension scores and cognitive load scale. Learners with a low aptitude for visual learning had poorer performance and a higher cognitive load than those with a high aptitude for visual learning. All learners, regardless of cognitive styles and level of English, benefited from dual coding. The dual-code display model thus seems to be effective in reducing EFL learners’ cognitive load.
\end{abstract}

\section{Introduction}

Videos are often used to assist learners of English as a Foreign Language (EFL) in learning English. Conversations found in videos, as spoken by native speakers, provide students with authentic material with which to learn foreign languages (Buck, 2001; Richards \& Rodgers, 2001; Rost, 1990). Real-life texts uttered by native speakers are generally spoken only once and not repeated unless they are recorded for a particular purpose. Recorded exchanges in the target language provide opportunities for EFL students to practice listening comprehension through repetition and review. The rapid delivery rate and transient nature of these authentic audios/videos impose a significant cognitive load on learners. Thus, it is assumed that multiple codes (i.e., audio plus visual, or audiovisual plus captions) can help reduce their cognitive load (Garza, 1991; Vanderplank, 1988) and enhance overall listening comprehension.

Factors relevant to individual differences that might affect multimedia learning include cognitive preference (Alloway, Banner, \& Smith, 2010; Chun \& Plass, 1996; Plass, Chun, Mayer, \& Leutner, 1998) and language proficiency (Mueller, 1980). It is assumed that visualisers depend more on imagery while verbalisers rely more on verbal inputs to learn. If visual aids or imagery are unavailable, visualizers will not benefit so much from the instructional material (e.g., Chen, Hsieh, \& Kinshuk, 2008). However, the lack of visual imagery does not adversely influence verbalisers' learning (e.g., Plass et al., 1998). Visualisers perform better in audiovisual conditions than those in audio-only conditions, whereas verbalisers perform just as well in audiovisual conditions as they do in audio-only conditions. In addition, Mueller (1980) has suggested that single mode learning is sufficient for high-prior-knowledge learners, whereas dual coding can compensate for low-prior-knowledge learners' inadequate knowledge. Therefore, learners with a low level of English proficiency benefit more from audiovisual learning conditions compared with those in audio-only conditions. However, learners with a high level of English proficiency perform as well in audiovisual conditions as those in audio-only conditions. Learners' language proficiency level interacts with the experimental treatment and influences their learning results.

Finally, learners might encounter a heavy cognitive load while watching authentic videos. The modality principle assumes that dual coding can reduce learners' extraneous load (Mayer \& Moreno, 2010) and facilitate learning. This study specifically expands upon research previously conducted on learning a foreign language as a second language (L2) listening in a multimedia environment with the aim of addressing the questions of whether dual coding can reduce learners' cognitive load, and how different types of cognitive learning styles and multimedia display models affect listening comprehension among learners with varying levels of English proficiency. This paper concludes with a discussion and pedagogical implications. 


\section{Literature review}

\section{Dual coding theory}

Visual and auditory inputs are first processed in the learner's working memory. The human cognitive system, with its limited capacity, cannot be alerted to all inputs, but rather selects key parts of auditory/visual messages by focusing on only the most relevant information. These visual and auditory messages constitute the dual codes involved in sensory reception. The dual codes include both verbal codes (i.e., logogens) and non-verbal codes (i.e., imagens) (Clark \& Paivio, 1991). The interaction that occurs within the verbal or the visual system is known as the associative connection, while the interaction between the verbal and non-verbal systems is referred to as the referential connection (Clark \& Paivio, 1991). The eyes receive recorded visual input in the form of graphic illustrations, animations, videos, and screen texts, while the ears receive sensory input in the form of verbal narration or through non-verbal sound cues. Visual channels process graphic material, while auditory channels process verbal material, according to Paivio's dual coding theory (Clark \& Paivio, 1991; Mayer, 2009). Dual coding theory can be applied to multimedia learning contexts (Mayer \& Moreno, 2010) in which the display model can be realised as pictures plus narration, pictures plus text plus narration, simulation or interactive games (Mayer, 2009). Learning typically occurs more effectively through dual coding than by visual or verbal coding alone (Jones, 2009; Mayer, 2009). Simultaneously processing both verbal and visual codes in working memory constructs a strong mental model (Gellevij, van der Meij, de Jong, \& Pieters, 2002) and enhances memory. The cognitive theory of multimedia learning suggests that a learner can learn better when the verbal code is integrated with visual images. The studies of Al-Seghayer (2001), Chun and Plass (1996), Chen et al. (2008), Homer, Plass, and Blake (2007), Jones (2004), Jones and Plass (2002), Leutner and Plass (1998), Plass et al. (1998, 2003), Yanguas (2009), and Yoshii and Flaitz (2002) all support dual coding theory and show that students learn more effectively in response to dual coding (i.e., pictorial plus written annotations) than they do in response to single coding (i.e., either written or pictorial annotations alone) in multimedia language learning environments.

\section{Cognitive load theory}

Based on the cognitive theory of multimedia learning, the initial learning process involves five steps: (1) selection of relevant words to process into working memory, (2) selection of relevant images to process into working memory, (3) organisation of selected words, (4) organisation of selected images, and (5) integration of visual and auditory information with prior knowledge (Horz \& Schnotz, 2010; Mayer, 2009). Learners may activate the knowledge to be retrieved from their long-term memory and then process the information in their working memory, thus establishing a link between the incoming message and their prior knowledge. If the message is further explained with illustrations, comprehension and retention of the message may be enhanced. However, there are also some impediments to learning that can have a direct effect on comprehension.

Three types of cognitive load may affect learning: extraneous, intrinsic, and germane. Poor instructional design can cause extraneous cognitive load (Mayer, 2009; Mayer \& Moreno, 2010; Moreno \& Mayer, 2010; Moreno \& Park, 2010) but the load may be minimised by improving spatial and temporal contiguity (Horz \& Schnotz, 2010; Mayer, 2005, 2009; Moreno \& Park, 2010). Intrinsic load is influenced by the learning material's relative complexity (Mayer, 2009; Mayer \& Moreno, 2010). Thus, learners must possess sufficient background knowledge for text comprehension to occur (Moreno \& Park, 2010). If the intrinsic load is light, a heavy extraneous load should not negatively affect learning. If the intrinsic load is too heavy, the addition of a heavy extraneous load will exceed the learners' working memory capacity. Germane load is caused by expending cognitive resources on schema acquisition and schema activation (Mayer \& Moreno, 2010; Moreno \& Mayer, 2010; Moreno \& Park, 2010). Since working memory capacity is limited, simultaneous transmission of inputs via several channels will overload a learner's memory capacity and negatively affect comprehension. Thus, the overall cognitive load should not exceed overall working memory capacity (Moreno \& Park, 2010). 


\section{Cognitive preference: visualisers vs. verbalisers}

Learners' cognitive style may also influence their learning efficiency. Visualisers depend on imagery to build up mental models, whereas verbalisers learn better through verbal cues and need not rely on visual aids as much as visualisers do (e.g., Plass et al., 1998). Dual coding theory assumes that multimedia material can help learners build up referential connections between visual and verbal representations. Learners with high visual ability can easily build up mental models between visual and verbal representations, whereas learners with low visual ability struggle to build up mental representations (e.g., Jones, 2009). As a result, visualisers benefit more from multimedia resources than do verbalisers (e.g., Plass et al., 1998). Learning outcomes of specific instructional materials may vary according to each learner's learning preference.

\section{Relevant studies on visual and verbal learning}

Chen et al. (2008) examined whether learners with different cognitive learning styles performed differently using different instructional materials in a mobile learning environment. The EFL learners were classified into one of four learning abilities: (a) high visual plus high verbal, (b) high visual plus low verbal, (c) low visual plus high verbal, and (d) low visual plus low verbal. All of the learners in each group were required to learn vocabulary through a mobile phone screen under four conditions: (a) English word only, (b) embedded English word with written annotations, (c) embedded English word with pictorial annotations, and (d) embedded English word with both written and pictorial annotations. The results show that in a mobile language learning environment, providing vocabulary with pictorial annotations helped learners with high visual plus low verbal abilities. Providing a vocabulary with both pictorial and written annotations helped learners with high visual plus high verbal abilities. However, providing too much information was not beneficial for learners with low verbal plus low visual abilities, because it substantially increased their cognitive load.

Plass et al. (1998) investigated the effects of pictorial and verbal annotations on vocabulary learning in a multimedia language learning environment. In their study, 103 English-speaking college students were classified as either visualisers or verbalisers. The students read a German story and were allowed to access either visual or verbal annotations, or both, whenever they encountered unfamiliar vocabulary. The results show that students learned best when the vocabulary was explained using both visual and verbal annotations. The learners also learned more effectively when the multimedia presentation model was suited to their learning preference. The visualisers performed worse when their preferred presentation model was unavailable.

Leutner and Plass (1998) examined the validity and reliability of a cognitive preference scale to discriminate visualisers and verbalisers by recruiting 103 native English speakers learning German. The results show that the verbalisers produced more correct definitions when using verbal cues, while the visualisers produced more correct definitions when using visual cues. The visualisers performed better on reading comprehension when both visual and verbal annotations were available compared to when there were only verbal annotations present. Both visual and verbal annotations helped the learners more than either visual or verbal annotations alone did.

Thomas and McKay (2010) investigated the learning of verbalisers, object-visualisers and spatial-visualisers under three conditions: a) text only, b) text plus picture, and c) text plus a schematic. The results show that the learners' cognitive styles predicted their comprehension and recall when their cognitive styles matched the presentation format. The learners' learning outcomes improved when instructional material matched their cognitive styles.

Jones (2009) examined spatial and verbal learners' vocabulary learning in the following multimedia environments: (a) no annotation, (b) written annotations, (c) pictorial annotations, and (d) written plus pictorial annotations. The results show no difference between learners with high and low spatial capabilities under the pictorial plus written annotations condition. However, learners with high verbal capabilities outperformed those with low verbal capabilities on recall and vocabulary tests in the pictorial annotations condition. No significant differences were found between learners with high and low verbal 
capabilities in the absence of annotations. Furthermore, learners with high spatial capabilities displayed comparable performance to those with low spatial capabilities on the dependent measures.

Mendelson and Thorson (2004) investigated news story comprehension among 123 freshmen by assigning learners to one of two different learning conditions: a) personal stories w/without photos, and b) professional stories $\mathrm{w} /$ without photos. The results show that the students with high verbal capabilities were more interested in the news stories than those with low verbal capabilities. Compared to the learners with low verbal capabilities, those with high verbal capabilities recalled more news stories when no photos accompanied the stories. Those with low verbal capabilities recalled more about the news stories when a photo was present. However, learners with high verbal capabilities recalled less of the content in the news stories, as the accompanying photos seemed to be more of a distraction. On the other hand, the learners with mid- and low verbal capabilities were aided by the photos in recalling the news stories. The recall ability of the visual learners was not determined by their visual capabilities. The learners with high-, mid-, and low-level visual capabilities recalled similar amounts of the content in the news stories with no significant difference among the groups. The learners with high visual capabilities did not benefit from photos in regard to their comprehension of the news stories likely due to the fact that all of the measures in their study were primarily in verbal form, thus providing the learners with visual capabilities with no opportunity to strengthen their visual memory.

Acha (2009) investigated children's Spanish vocabulary learning under three conditions: text only, picture only, and text plus picture. The children in the text-only group outperformed those in the other two groups in vocabulary learning. That is, visual learners did not gain more benefits from multimedia as hypothesised, suggesting that too much information in visual and verbal forms impose an unmanageable cognitive load on children.

Also, Plass et al. (2003) found that learners acquired more vocabulary when both visual and verbal annotations were available than when either visual or verbal annotations, or no annotations were present. In their study, both low spatial and low verbal learners performed worse than those with high spatial and high verbal capabilities when visual annotations were available, but not when verbal annotations were available. The learners' text comprehension was better when they received verbal annotations than when they received no annotations, visual annotations, or visual plus verbal annotations. While the learners were processing verbal information, selecting and processing additional visual or visual plus verbal information helped them invest more cognitive resources to construct referential connections between pictures and words. When annotations were absent, the investment of cognitive resources on vocabulary processing would be unnecessary, they would focus all cognitive resources on text comprehension. Thus, visual information may not be the sole factor to text comprehension.

\section{Statement of the problem}

The debate over whether presentation format supports individual differences in achieving more successful learning (e.g., Chen et al., 2008; Höffler \& Leutner, 2011; Homer et al., 2007; Plass et al., 1998; Thomas \& McKay, 2010) or does not support this notion (e.g., Acha, 2009; Jones, 2009; Mendelson \& Thorson, 2004; Plass et al., 2003) remains inconclusive. Learners' learning preference has been addressed more frequently in regard to low-level (i.e., bottom-up) cognitive processing of vocabulary, but has been minimally explored in high-level (i.e., top-down) cognitive processing of listening comprehension. In addition, language proficiency influences learning results (Chun \& Plass, 1996). Multimedia is especially effective for learners with minimal prior knowledge and for high visual ability learners.

Finally, dual coding theory is challenged by cognitive load theory. Cognitive load theory states that redundant codes overload learners' capacity to process information. However, dual coding theory assumes that learners benefit more from dual codes than from a single code. There seems to be little research that has measured learners' cognitive loads when they engage in multimedia learning. Learning preferences, prior knowledge and learning environment may affect learning outcomes and cognitive load (Brunken, Seufert, \& Paas, 2010). 
The aim of the present study is to investigate how learners' cognitive style, language proficiency levels and various experimental treatments affect learning results and cognitive load. To address these unresolved questions, the research questions in the present study are as follows:

1. Do students perform differently on listening comprehension tests in different learning conditions?

2. How much of a cognitive load do learners in different conditions experience?

3. Do English proficiency level, cognitive preference and experimental treatment affect EFL learners' listening comprehension and cognitive load?

\section{Methodology}

\section{Participants}

The subjects in the study were sophomores enrolled in a foreign language department at a science and technology university in southeast China. None of the students had prior experience traveling in English-speaking countries. None of the subjects had previously heard or watched the news broadcasts used in the present research.

\section{Independent variables}

\section{English proficiency level}

A GEPT ${ }^{1}$ intermediate listening test (equivalent to the international standard of TOEFL iBT 79-100) was first administered to the participants in order to assess their English proficiency level. There were a total of 103 students (male $=18$, female $=85$ ) with an overall average age of about $20($ mean $=20.6, S D=0.9)$. An independent sample t-test revealed no significant difference between the experimental and control groups, $t(101)=-.907, p>0.05$. The students' English ability was comparable before the formal study commenced. The top 30\% were classified as high proficiency learners, while the lowest $30 \%$ were classified as low proficiency learners. The students whose proficiency level fell between that of the high and low proficiency learners were excluded from the data analyses, leaving a total of 87 students in the study.

\section{Cognitive style measurement}

The learners' cognitive styles were identified using the index of learning styles questionnaire, developed by Felder and Soloman (1997). The questionnaire is comprised of 44 alternative-choice questions. Based on the students' ratings on the measurement, students were classified into one of three cognitive learning types: (a) high-lever visual learners, (b) mid-level visual learners, and (c) low-level visual learners. Students whose rating was at or above an index of 5 on the visual scale were classified as high-level visual learners. Those students with a rating at an index of 3 on the visual scale were classified as mid-level visual learners. Those with a rating at an index of 1 on the visual scale were classified as low-level visual learners. Students in both the experimental and the control groups comprised these three types of learners.

\section{Experimental treatment}

The students in the control group received audio content only (single code), while students in the experimental group received audiovisual content (dual codes). The control group listened to each of three audio recordings (CNN news broadcasts). Students in the experimental group viewed the same news broadcasts presented as video clips. The experimental and the control groups sat identical tests, although these were administered at different times.

\section{Dependent variables}

Listening comprehension test - immediate test

The students' comprehension of the news content was determined by administering a test containing true/false and multiple-choice type questions. The questions were taken directly from the book Master Listening with CNN News (Live ABC, 2011) (with a difficulty level comparable to that of 100-117 on the 
TOEFL iBT). In the true/false section, the questions were meant to examine the students' understanding of the general content and scope of the news broadcasts. The questions in the multiple-choice section were aimed at examining the students' understanding of specific information in the broadcasts, such as proper nouns, time, place, date, figure, and key words relevant to the news broadcasts. The students answered the true/false questions before they did the multiple-choice questions. Each correct answer was worth one point.

Listening comprehension tests - delayed test

Students received an unannounced delayed test two weeks after the experiment. The test items in the delayed test and the immediate test were identical.

\section{Cognitive load measurement}

Students in both the experimental and the control groups were given a self-rated cognitive load measurement questionnaire.

\section{Instructional material overview}

CNN news broadcasts related to commerce were employed in conducting the experiment. The spoken texts in the CNN news were authentic and unedited. Each video segment lasted for approximately 2.5 minutes. An example of a screen shot of the audio display model is shown in Figure 1, and an example of a screen shot of the video is shown in Figure 2. The broadcasts were delivered by a news anchor or consisted of interviews between an interviewer (i.e., a news reporter) and interviewees. There was a high audio-to-visual correspondence, that is, videos did not just consist of talking heads.

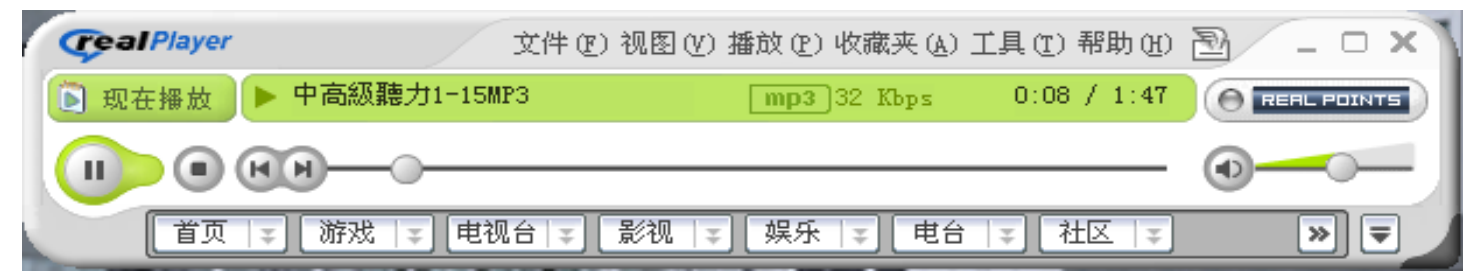

Figure 1. Screen shot of a single-code model used in the control group

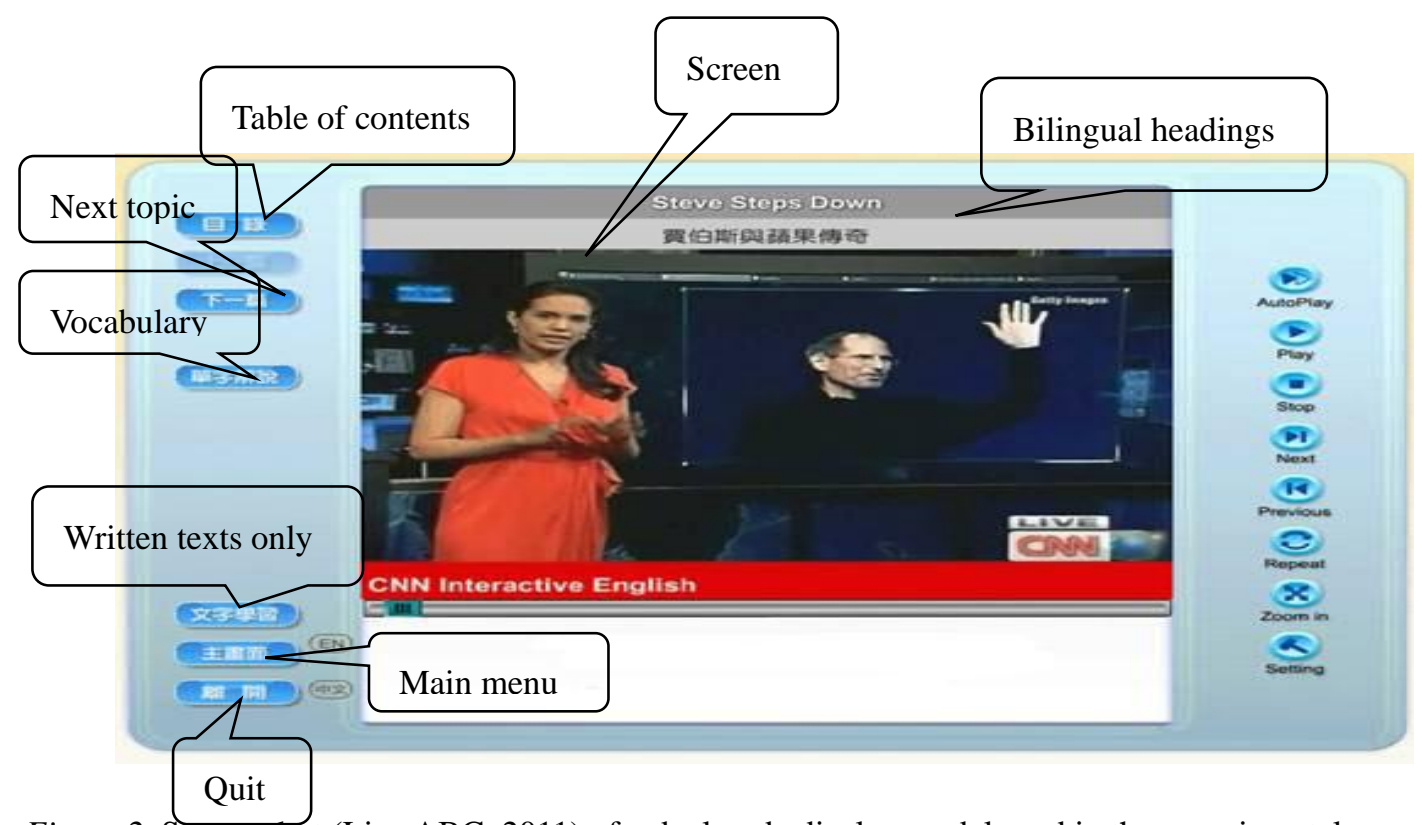

Figure 2. Screen shot (Live ABC, 2011) of a dual-code display model used in the experimental group 


\section{Experimental procedures}

The experiment was conducted in a language laboratory containing 110 student seats and a computerised teacher control system from which the teacher could control the computer system and monitored all students. The researcher sat at the computer system in order to control the volume, CD player, and the presentation modes of the videos, and to turn on/off the computer monitors as necessary. The sound was played through four speakers (two in front and two at the back of the laboratory), ensuring that the sound was loud enough for everyone to hear clearly. The experiment was conducted during the students' regular class period.

First, the researcher gave the students instructions regarding the following: (1) the GEPT format as a pre-test, (2) the cognitive style measurement and listening comprehension tests, (3) how to participate in listening activities pertaining to listening passages or videos context, and (4) what they were and were not allowed to do during the tests, (5) how to complete the cognitive load measurement instrument, and (6) procedures that needed to be completed following the experiment.

Prior to conducting the experiment itself, the students were first required to take the GEPT listening test as a pre-test to evaluate their English proficiency level. Secondly, they completed the index of learning styles questionnaire developed by Felder and Soloman (1997). Thirdly, they listened to the audio or watched the video clips and did the accompanying listening activities. Fourthly, they undertook the listening comprehension test immediately after listening to or watching each news broadcast. The comprehension questions were displayed on each student's computer monitor at their seat, and the students responded by writing down their answer choices on an answer sheet. The students were not permitted to take notes, talk to their peers, or use a dictionary while taking the comprehension tests, but were permitted to do the paper and pencil test at their own rate. The experimental design is shown in Table 1.

Table 1

Experimental design

\begin{tabular}{lll}
\hline Groups & Audio only & Audiovisual \\
\hline & Single code & Dual codes \\
News $1 \sim 3$ & CG $(N=44)$ & EG $(N=43)$ \\
Learning style & Audio x 3 times & Audiovisual x 3 times \\
& High-level visual = 12 & High-level visual = 15 \\
& Mid-level visual = 14 & Mid-level visual = 15 \\
English proficiency & Low-level visual = 18 & Low-level visual = 13 \\
& High $=18$ & High $=19$ \\
& Low $=26$ & Low $=24$ \\
\hline
\end{tabular}

Note. CG refers the control group; EG refers to the experimental group

\section{Data collection instruments}

The listening comprehension test

The students' comprehension of the video content was examined through true/false and multiple-choice questions.

\section{Cognitive style measurement}

Only the visual and verbal scales in the index of learning styles questionnaire (Felder \& Soloman, 1997) were considered in the present study. The strength of the style was indicated by an index ranging from 1 to 11, with 1 representing the lowest level and 11 representing the highest level.

\section{Cognitive load measurement}

The cognitive load measurement instrument comprised 8 items. For each item, the index ranged from 1 to 7, with index 1 representing the lowest level (i.e., extremely low or extremely easy) and index 7 representing the highest level (i.e., extremely high or extremely difficult). 


\section{Reliability of data collection instruments}

A pilot study involving 71 seniors in the applied English department was conducted prior to the experiment. The reliability of each measurement was as follows:

\section{GEPT listening test}

Point-biserial correlation was used to exclude weak test items which failed to discriminate between high and low proficiency learners. The Cronbach's alpha for the GEPT was 0.992 indicating high reliability (Wu \& Tu, 2006).

\section{Listening comprehension test}

Point-biserial correlation was also conducted to eliminate weak test items which failed to discriminate between high- and low-level learners (Wu \& Tu, 2006). The test comprised 30 questions, 6 true/false and 4 multiple-choice for each of 3 CNN news broadcasts. However, following item analysis, 6 questions were removed. The Cronbach’s alpha for the listening comprehension test was 0.769 .

Cognitive style and load measurements

The Cronbach’s alpha for the cognitive style and load measures were 0.89 and 0.818 respectively.

\section{Data analysis instrument}

The data were analysed using both Excel and SPSS software (Statistical Package for the Social Sciences) for Windows 15.0 to explain the research questions. The significance level was set at .05. An independent sample t-test was used to analyse the difference in scores on the immediate and the delayed listening comprehension test as well as the differences in cognitive load between the control and the experimental groups. A three-way ANOVA was used to analyze the interaction among English proficiency level, experimental treatment and cognitive learning style.

\section{Results}

\section{Research question 1}

The results of the independent sample t-test reveal a highly significant difference between the two groups (i.e., single vs. dual code) on the immediate listening test, $t(85)=-5.068, p<.05$. These results were also confirmed in the delayed test, $t(85)=-5.013, p<.05$. The students in the dual-code group outperformed their counterparts (Table 2).

Table 2

Independent sample t-test for CNN comprehension test

\begin{tabular}{lcccccc}
\hline & $N$ & $M$ & $S D$ & $t$ & $d f$ & $p$ \\
\hline Immediate test & & & & & & \\
\hline Single code & 44 & 11.57 & 3.083 & & & \\
Dual codes & 43 & 14.86 & 2.973 & -5.068 & 85 & $.000^{* * *}$ \\
\hline Delayed test & & & & & & \\
\hline Single code & 44 & 10.43 & 2.984 & & & \\
Dual codes & 43 & 13.79 & 3.263 & -5.013 & 85 & $.000^{* * *}$ \\
$* p<.05, * * p<.01, * * * 0.001$ & & & & & &
\end{tabular}

\section{Research question 2}

The learners' attitudes regarding cognitive load were analysed using an independent sample t-test-the results of which are presented in Table 3 . The results show a significant difference between groups in regard to item $1, t(85)=2.78, p<.05$. The students in the single code group (SCG) felt the listening passages were difficult and the index was significantly higher than it was for those in the dual-code group (DCG). There was also a significant difference in item $2, t(85)=2.60, p<.05$. Those in the SCG felt the listening passages were very difficult and the index was significantly higher than it was for those in the 
DCG. Item 3 showed no significant difference, $t(85)=.902, p>.05$. Students in both the experimental and the control groups felt they had to exert much mental effort to understand the broadcasts. Although the control group had a higher index, it did not reach a significant level. There was a significant difference in item $4, t(85)=2.033, p<.05$. Students in the control group felt the listening text and comprehension questions were both more difficult to understand than did those in the experimental group. There was no significant difference in item $5, t(85)=.98, p>.05$. Students in both the control and the experimental groups felt the pace of the task was too fast, but no significant difference was found. Similarly, there was no significant difference in item $6, t(85)=1.27, p>.05$. Although students in the control group were less confident in completing the task compared to those in the experimental group, there was no significant difference between the two. However, a significant difference was found in item 7, $t(85)=2.80, p<.05$. Students in the SCG felt it was harder to reach their level of performance than did those in the DCG. There was also a significant difference in item $8, t(85)=4.62, p<.05$. Students in the SCG felt more insecure, discouraged, irritated and annoyed than did those in the DCG.

Table 3

Independent sample t-test comparing cognitive load in single-and dual-codes group

\begin{tabular}{|c|c|c|c|c|c|c|c|}
\hline Cognitive load scale & Group & $N$ & $M$ & $S D$ & $t$ & $d f$ & $p$ \\
\hline 1. The difficulty level of the overall listening & Single & 44 & 5.91 & 1.053 & 2.78 & 85 & $.007^{* *}$ \\
\hline passage is... & Dual & 43 & 5.26 & 1.136 & & & \\
\hline 2. To understand the overall listening & Single & 44 & 5.75 & 1.014 & 2.60 & 85 & $.011^{* *}$ \\
\hline passage is... & Dual & 43 & 5.19 & 1.006 & & & \\
\hline 3. To understand the overall listening & Single & 44 & 5.91 & 1.197 & 0.902 & 85 & .370 \\
\hline passage, the mental effort I have expended is & Dual & 43 & 5.67 & 1.229 & & & \\
\hline 4. How difficult was it for you to understand & Single & 44 & 5.66 & 1.238 & 2.03 & 85 & $.045^{*}$ \\
\hline $\begin{array}{l}\text { this learning module and correctly answer } \\
\text { the comprehension questions? }\end{array}$ & Dual & 43 & 5.02 & 1.655 & & & \\
\hline 5. How hurried or rushed was the pace of & Single & 44 & 5.80 & 1.047 & 0.983 & 85 & .328 \\
\hline the task? & Dual & 43 & 5.56 & 1.201 & & & \\
\hline 6. How successful did you feel when you & Single & 44 & 5.28 & 1.207 & 1.27 & 85 & .207 \\
\hline $\begin{array}{l}\text { were accomplishing what you were asked to } \\
\text { do? }\end{array}$ & Dual & 43 & 5.59 & 1.076 & & & \\
\hline 7. How hard did you have to work to & Single & 44 & 6.05 & 1.196 & 2.80 & 85 & $.006 * *$ \\
\hline accomplish your level of performance? & Dual & 43 & 5.32 & 1.234 & & & \\
\hline 8. How insecure, discouraged, irritated, and & Single & 44 & 6.34 & 0.888 & 4.62 & 85 & $.000 * * *$ \\
\hline annoyed were you? & Dual & 43 & 5.33 & 1.149 & & & \\
\hline
\end{tabular}

\section{Research question 3}

A three-way ANOVA was conducted to examine the interactive effects among the experimental conditions, cognitive style, and English proficiency level on the listening comprehension test. In Table 6, the ANOVA source of variation results indicate no significant interaction among experimental condition, cognitive style, and English proficiency, $F(2,75)=.883, p=.418$. However, the main effect of the experimental condition was statistically significant, $F(1,75)=26.705, p=.000$. The DCG $(M=14.86$, $S D=2.973)$ was significantly higher than the SCG $(M=11.57, S D=3.083)$ in terms of total score, $p$ $=.000$. The main effect of English proficiency level was also statistically significant, $F(1,75)=11.325, p$ $=.001$. The high proficiency learners $(M=14.43, S D=3.686)$ performed significantly better than the low proficiency learners $(M=12.28, S D=2.956), p=.001$. The main effect of cognitive style was not statistically significant, $F(2,75)=.848, p=.432$. 
Table 4

Listening comprehension scores in different conditions

\begin{tabular}{|c|c|c|c|c|c|c|c|c|}
\hline \multirow[b]{2}{*}{ Style } & \multirow[b]{2}{*}{ Mean } & \multirow[b]{2}{*}{$S D$} & \multicolumn{3}{|c|}{ Single code } & \multicolumn{3}{|c|}{ Dual codes } \\
\hline & & & English $(N)$ & Mean & $S D$ & English $(N)$ & Mean & $S D$ \\
\hline \multirow{3}{*}{$\begin{array}{l}\text { High-level } \\
\text { visual }\end{array}$} & 13.78 & 2.96 & $\operatorname{High}(N=5)$ & 14.40 & 2.966 & $\operatorname{High}(N=6)$ & 16.33 & 2.422 \\
\hline & & & Low $(N=7)$ & 11.29 & 2.138 & Low $(N=9)$ & 13.67 & 2.345 \\
\hline & & & Total & 12.58 & 2.875 & Total & 14.73 & 2.658 \\
\hline \multirow{3}{*}{$\begin{array}{l}\text { Mid-level } \\
\text { visual }\end{array}$} & 13.17 & 3.82 & $\operatorname{High}(N=5)$ & 10.80 & 3.271 & $\operatorname{High}(N=6)$ & 17.33 & 2.805 \\
\hline & & & Low $(N=9)$ & 11.00 & 3.000 & Low $(N=9)$ & 13.89 & 3.060 \\
\hline & & & Total & 10.93 & 2.973 & Total & 15.27 & 3.348 \\
\hline \multirow{4}{*}{$\begin{array}{l}\text { Low-level } \\
\text { visual }\end{array}$} & 12.71 & 3.51 & High $(N=8)$ & 11.75 & 3.370 & $\operatorname{High}(N=7)$ & 16.00 & 2.887 \\
\hline & & & Low $(N=10)$ & 11.10 & 3.381 & Low $(N=6)$ & 12.83 & 2.401 \\
\hline & & & Total & 11.39 & 3.292 & Total & 14.54 & 3.045 \\
\hline & & & Total (44) & 11.57 & 3.083 & Total (43) & 14.86 & 2.973 \\
\hline
\end{tabular}

Table 5

Performance on CNN listening task by English and style

\begin{tabular}{llcc}
\hline English & Style $(N)$ & Mean & $S D$ \\
\hline High & High-level visual $(N=11)$ & 15.45 & 2.734 \\
& Mid-level visual $(N=11)$ & 14.36 & 4.456 \\
& Low-level visual $(N=15)$ & 13.73 & 3.751 \\
\multirow{3}{*}{ Low } & Total $(N=37)$ & 14.43 & 3.686 \\
& High-level visual $(N=16)$ & 12.63 & 2.500 \\
& Mid-level visual $(N=18)$ & 12.44 & 3.294 \\
& Low-level visual $(N=16)$ & 11.75 & 3.088 \\
& Total $(N=50)$ & 12.28 & 2.956 \\
\hline
\end{tabular}

Table 6

Three-way ANOVA of group $x$ English $x$ style

\begin{tabular}{lrrrrrr} 
Source & Type III sum of squares & df & Mean square & \multicolumn{1}{c}{ F } & Sig. & $\eta^{2}$ p \\
\hline group & 222.971 & 1 & 222.971 & 26.705 & $.000^{* * *}$ & .263 \\
English & 94.561 & 1 & 94.561 & 11.325 & $.001^{* *}$ & .131 \\
style & 14.168 & 2 & 7.084 & .848 & .432 & .022 \\
group * English & 18.717 & 1 & 18.717 & 2.242 & .139 & .029 \\
group * style & 22.654 & 2 & 11.327 & 1.357 & .264 & .035 \\
English * style & 5.844 & 2 & 2.922 & .350 & .706 & .009 \\
group * English * style & 14.738 & 2 & 7.369 & .883 & .418 & .023 \\
Error & & 75 & 8.350 & & & \\
${ }^{* p<.05, * * p<.01,{ }^{* * *} p<.001}$ & & & & & &
\end{tabular}

To conclude the results in the listening comprehension analyses, those in the dual-code display model performed significantly better than those in the single code display model. Moreover, the high proficiency learners significantly outperformed their low proficiency counterparts. Overall, all three types of learners, regardless of English proficiency and cognitive style, were assisted in their learning through the use of dual codes.

A three-way ANOVA was conducted to examine interactive effects among the experimental conditions, cognitive style, and English proficiency on cognitive load. In Table 9, the ANOVA source of variation results indicate no significant interaction among the experimental condition, cognitive style, and English proficiency, $F(2,75)=1.601, p=.209$. However, the main effect of experimental condition was statistically significant, $F(1,75)=5.818, p=.018$. The cognitive load of the SCG $(M=43.27, S D=4.785)$ was significantly higher than that of the DCG $(M=40.35, S D=5.089), p=.018$ as indicated on the cognitive load scale. The main effect of English proficiency level was not statistically significant, $F(1,75)$ $=1.262, p=.265$. The cognitive load for the low proficiency learners $(M=42.32, S D=5.255)$ was not significantly higher than it was for the high proficiency learners $(M=41.16, S D=4.936), p=.265$ while 
listening to/watching the broadcasts and completing the required tasks. The main effect of cognitive style was not statistically significant, $F(2,75)=.243, p=.785$. The low-level visual learners had a higher cognitive load $(M=42.42, S D=5.10)$ than either the high- $(M=41.63$, $S D=4.70)$ or the mid-level visual learners $(M=41.38, S D=5.62)$, but this difference was not statistically significant.

Table 7

Cognitive load under various conditions

\begin{tabular}{|c|c|c|c|c|c|c|c|c|}
\hline \multirow[b]{2}{*}{ Style } & \multirow[b]{2}{*}{ Mean } & \multirow[b]{2}{*}{$S D$} & \multicolumn{3}{|c|}{$\begin{array}{l}\text { Single code } \\
\end{array}$} & \multicolumn{3}{|c|}{ Dual codes } \\
\hline & & & English $(N)$ & Mean & $S D$ & English $(N)$ & Mean & $S D$ \\
\hline High-level & 41.63 & 4.70 & $\operatorname{High}(N=5)$ & 41.00 & 3.391 & $\operatorname{High}(N=6)$ & 42.00 & 4.604 \\
\hline \multirow{2}{*}{ visual } & & & Low $(N=7)$ & 43.86 & 3.436 & Low $(N=9)$ & 40.00 & 6.021 \\
\hline & & & Total & 42.67 & 3.576 & Total & 40.80 & 5.414 \\
\hline Mid-level & 41.38 & 5.62 & $\operatorname{High}(N=5)$ & 43.00 & 4.359 & $\operatorname{High}(N=6)$ & 38.50 & 6.804 \\
\hline \multirow[t]{2}{*}{ visual } & & & Low $(N=9)$ & 43.22 & 6.942 & Low $(N=9)$ & 40.56 & 3.395 \\
\hline & & & Total & 43.14 & 4.685 & Total & 39.73 & 5.238 \\
\hline \multirow{4}{*}{$\begin{array}{l}\text { Low-level } \\
\text { visual }\end{array}$} & 42.42 & 5.10 & $\operatorname{High}(N=8)$ & 43.88 & 4.491 & $\operatorname{High}(N=7)$ & 38.43 & 3.457 \\
\hline & & & Low $(N=10)$ & 43.70 & 4.739 & Low $(N=6)$ & 43.00 & 6.164 \\
\hline & & & Total & 43.78 & 5.960 & Total & 40.54 & 4.920 \\
\hline & & & Total (44) & 43.27 & 4.785 & Total (43) & 40.35 & 5.089 \\
\hline
\end{tabular}

Table 8

Cognitive load by English level

\begin{tabular}{llcc}
\hline English & Style & Mean & $S D$ \\
\hline High & High-level visual $(N=11)$ & 41.55 & 3.934 \\
& Mid-level visual $(N=11)$ & 40.55 & 6.023 \\
& Low-level visual $(N=15)$ & 41.33 & 5.024 \\
& Total $(N=37)$ & 41.16 & 4.936 \\
\multirow{2}{*}{ Low } & High-level visual $(N=16)$ & 41.69 & 5.288 \\
& Mid-level visual $(N=18)$ & 41.89 & 5.476 \\
& Low-level visual $(N=16)$ & 43.44 & 5.125 \\
& Total $(N=50)$ & 42.32 & 5.255 \\
\hline
\end{tabular}

Table 9

Three-way ANOVA English x group $x$ style on cognitive load scale

\begin{tabular}{|c|c|c|c|c|c|c|}
\hline Source & Type III sum of squares & df & Mean square & $\mathrm{F}$ & Sig. & $\eta_{p}^{2}$ \\
\hline group & 149.925 & 1 & 149.925 & 5.818 & $.018 *$ & .072 \\
\hline English & 32.523 & 1 & 32.523 & 1.262 & .265 & .017 \\
\hline style & 12.512 & 2 & 6.256 & .243 & .785 & .006 \\
\hline group * English & 1.701 & 1 & 1.701 & .066 & .798 & .001 \\
\hline group $*$ style & 16.744 & 2 & 8.372 & .325 & .724 & .009 \\
\hline English * style & 11.108 & 2 & 5.554 & .216 & .807 & .006 \\
\hline group * English * style & 82.515 & 2 & 41.258 & 1.601 & .209 & .041 \\
\hline Error & & 75 & 25.771 & & & \\
\hline
\end{tabular}

In summary, with respect to the cognitive load level analyses, those in the SCG experienced significantly higher cognitive load than did those in the DCG. Although the low English proficiency learners had a somewhat higher cognitive load than did the high English proficiency learners; and the low-level visual learners had higher cognitive load than did the high- and mid-level visual learners, these differences were not significant. Thus, all students, regardless of their cognitive styles and English proficiency, appeared to experience similar cognitive loads. 


\section{Discussion}

\section{Dual coding}

Those in the DCG significantly outperformed their counterparts in the SCG on both the immediate and delayed tests, suggesting that the dual-code display model was more beneficial for learning. These results are consistent with previous studies that support dual coding theory (e.g., Chen et al., 2008; Jones, 2009; Jones \& Plass, 2002; Leutner \& Plass, 1998; Plass et al., 1998, 2003; Schmidt-Weigand \& Scheiter, 2011; Schwamborn, Thillmann, Opfermann, \& Leutner, 2011; Thomas \& McKay, 2010), and confirm that overall, students learn more effectively when presented with contents represented as dual codes rather than just a single code (Clark \& Paivio, 1991; Mayer, 2009). The integration of verbal inputs and visual imagery appears to enhance memory, thus enabling the students in the experimental group to outperform their counterparts on the delayed test.

\section{Cognitive load}

Examination of the learners' cognitive load under the experimental conditions of this study reveals that those in the DCG had lower ratings of cognitive load than did those in the SCG, implying that the dual-code display model reduces learners' cognitive load when exposed to authentic foreign language content. However, both high and low proficiency learners had similar cognitive loads and levels of anxiety while listening to/watching foreign language news broadcasts. This suggests that the dual-code display model can help reduce the cognitive load of both low and high proficiency learners. For the high-level visual learners, the high-level visual learners with high English proficiency had similar cognitive loads in both the single and dual-code conditions. However, low learning proficiency learners displayed an extremely high cognitive load when given a single code. When presented with dual codes, however, their cognitive load decreased dramatically. This was due first to their learning style. High-level visual learners relied heavily on visual imagery; however, when they were deprived of their preferred learning model, their anxiety levels increased. Secondly, it was probably due to their low English proficiency. Providing them with audiovisual materials could compensate for their low English proficiency, and helped lessen their anxiety and reduce their cognitive load. The mid-level visual learners in the DCG (both high and low proficiency learners) had a lower cognitive load than did those in the SCG. The low-level visual learners in the SCG (both high and low proficiency learners) displayed higher cognitive loads than did those in the DCG. When the low-level visual learners with high English proficiency were presented with dual codes, their cognitive load declined dramatically. However, when the low-level visual learners with low English proficiency were presented with dual codes, their cognitive load remained consistently high. This was likely due to two reasons. First, their low English proficiency likely made comprehension of the listening passages difficult. Secondly, their learning preference (i.e., low-level visual) prevented them from relying much on verbal and/or visual stimuli. Thus, even when they were presented with dual codes, they did not benefit from the visual imagery. Therefore, regardless of whether the low-level visual learners with low English proficiency were presented with single or dual codes, their cognitive load remained high.

Despite some evidence that the low English proficiency learners had higher cognitive loads than high English proficiency learners, and the low-level visual learners had higher cognitive loads than mid- and high-level visual learners, these differences were not significant. This differs from the results of previous studies (e.g., Acha, 2009; Chen et al., 2008; Homer et al., 2007; Plass et al., 2003), which found that too much information in a multimedia format can impose excess pressure on low-level visual/verbal learners. Possibly, the transient nature of CNN news was equally challenging to all learners. If the learners' English proficiency was too low and their preferred learning model was not supported, then their learning was likely to be compromised.

\section{Cognitive style}

The high-level visual learners with high English proficiency had similar performance and cognitive loads in both the DCG and the SCG. The high-level visual learners with low English proficiency displayed better performance and lower cognitive loads in the DCG than did those in the SCG, while the mid-level 
visual learners with high proficiency appeared to benefit most from dual coding. However, no statistical evidence was observed in the present study. The results in the present study were not in line with Höffler and Leutner's (2011) study, which supported the spatial-ability-as-compensator hypothesis. In their study, learners with high spatial-visualisation ability performed similarly well when presented with either static pictures or animation, whereas learners with low spatial-visualisation ability performed worse when given static pictures (as compared with animation). The results in the present study, however, somewhat corroborate the findings of Jones (2009). In her study, both high and low spatial learners performed similarly in a multimedia language learning environment.

\section{Conclusions}

From the above study, we can only conclude that all learners, regardless of cognitive styles, benefit from dual coding. That is, students can learn better using two codes rather than just one (Mayer, 2009). Moreover, the present study has demonstrated that the dual-code display model benefits all students, not especially low English proficiency learners. Also, learners of all cognitive styles, regardless of visual levels, also performed similarly in a multimedia language learning environment. There is no statistical evidence to support the idea that a multimedia learning environment supports individual differences.

\section{Limitations of the present research}

Probably due to the limited sample size, no statistical evidence was observed to support the idea that high-level visual learners with low English proficiency benefit from a multimedia learning environment. A higher number of participants in the experiment might provide sufficient evidence to show that multimedia learning supports individual differences. We were unable to identify many verbal learners within the current study. Future researchers should attempt to ensure a better balance between visual and verbal learners to make comparison to validate this notion. Besides, the cognitive load scales in the present research only measured general cognitive loads; future researchers may further examine specific aspects of learners' cognitive loads by other objective or subjective measurements.

\section{Note}

1. The GEPT (General English Proficiency Test) is developed by Taiwan's LTTC (Language Training and Testing Center). GEPT tests are comprised of four levels - elementary, intermediate, high-intermediate and advanced - to suit EFL learners of different English proficiency. Each level of the GEPT test includes listening, speaking, reading and writing components. The intermediate listening test includes three sections: picture recognition, short conversations, and longer dialogues. Each of these three sections contains 15 multiple-choice questions for a total of 45 questions. The highest possible score for the overall test is 120 , with 80 as passing. The GEPT is similar to other international standardised tests, such as TOEFL and TOEIC.

\section{References}

Acha, J. (2009). The effectiveness of multimedia programmes in children’s vocabulary learning. British Journal of Educational Technology, 40(1), 23-31.

Al-Seghayer, D. (2001). The effect of multimedia annotation modes on L2 vocabulary acquisition: A comparative study. Language Learning and Technology, 5(1), 202-232.

Alloway, T. P., Banner, G., \& Smith, P. (2010). Working memory and cognitive style in adolescents’ attainment. British Journal of Educational Psychology, 80, 567-581.

Brunken, R., Seufert, T., \& Paas, F. (2010). Measuring cognitive load. In J. L. Paas, R. Moreno, \& R. Brunken (Eds.), Cognitive load theory (pp.181-202). New York, NY: Cambridge University Press.

Buck, G. (2001). Assessing listening. New York, NY: Cambridge University Press.

Chen, N. S., Hsieh, S. W., \& Kinshuk. (2008). Effects of short term memory and content representation type on mobile language learning. Language Learning and Technology, 12(3), 93-113.

Chun, D. M., \& Plass, J. L. (1996). Effects of multimedia annotations on vocabulary acquisition. The Modern Language Journal, 80(2), 183-198.

Clark, J. M., \& Paivio, A. (1991). Dual coding theory and education. Educational Psychology Review, 
3(3), 149-210.

Felder, R. M., \& Soloman, B. A. (1997). Index of learning styles questionnaire. Retrieved from http://www.engr.ncsu.edu/learningstyles/ilsweb.html

Garza, T. J. (1991). Evaluating the use of captioned video materials in advanced foreign language learning. Foreign Language Annals, 24(3), 239-258.

Gellevij, M., van der Meij, H., de Jong, T., \& Pieters, J. (2002). Multimodal versus unimodal instruction in a complex learning context. The Journal of Experimental Education, 70(3), 215-239.

Höffler, T. N., \& Leutner, D. (2011). The role of spatial ability in learning from instructional animations - Evidence for an ability-as-compensator hypothesis. Computers in Human Behavior, 27, 209-216.

Homer, B. D., Plass, J. L., \& Blake, L. (2007). The effects of video on cognitive load and social presence in multimedia-learning. Computers in Human Behavior, 24, 786-797.

Horz, H., \& Schnotz, W. (2010). Cognitive load in learning with multiple representations. In J. L. Plass, R. Moreno \& R. Brunken (Eds.), Cognitive load theory (pp. 229-252). New York, NY: Cambridge University Press.

Jones, L. C. (2004). Testing L2 vocabulary recognition and recall using pictorial and written test items. Language Learning and Technology, 8(3), 122-143.

Jones, L. C. (2009). Supporting student difference in listening comprehension and vocabulary learning with multimedia annotation. CALICO Journal, 26(2), 267-289.

Jones, L. C., \& Plass, J. L. (2002). Supporting listening comprehension and vocabulary acquisition in French with multimedia annotations. The Modern Language Journal, 86(4), 546-561.

Leutner, D., \& Plass, J. L. (1998). Measuring learning styles with questionnaires versus direct observation of preferential choice behavior in authentic learning situations: The visualizer verbalizer behavior observation scale (VV-BOS). Computers in Human Behavior, 14(4), 543-557.

Live ABC. (2011). Master listening with CNN news. Taipei: Hebron.

Mayer, R. E. (2005). Principles for managing essential processing in multimedia learning: segmenting, pretraining, and modality principles. In R. E. Mayer (Ed.), The Cambridge handbook of multimedia learning (pp.169-182). New York, NY: Cambridge University Press.

Mayer, R. E. (2009). Multimedia learning (2nd ed.). Cambridge, MA: Cambridge University Press.

Mayer, R. E., \& Moreno, R. (2010). Techniques that reduce extraneous cognitive load and manage intrinsic cognitive load during multimedia learning. In J. L. Plass, R. Moreno \& R. Brunken (Eds.), Cognitive load theory (pp. 131-152). New York, NY: Cambridge University Press.

Mendelson, A. L., \& Thorson, E. (2004). How verbalizers and visualizers process the newspaper environment. Journal of Communication, 54, 474-491.

Moreno, R., \& Mayer, R. E. (2010). Techniques that increase generative processing in multimedia learning: open questions for cognitive load research. In J. L. Plass, R. Moreno \& R. Brunken (Eds.), Cognitive load theory (pp. 153-177). New York, NY: Cambridge University Press.

Moreno, R., \& Park, B. (2010). Cognitive load theory: historical development and relation to other theories. In J. L. Plass, R. Moreno \& R. Brunken (Eds.), Cognitive load theory (pp. 9-28). New York, NY: Cambridge University Press.

Mueller, G. A. (1980). Visual contextual cues and listening comprehension: An experiment. The Modern Language Journal, 64(3), 335-340.

Plass, J. L., Chun, D. M., Mayer, R. E., \& Leutner, D. (1998). Supporting visual and verbal learning preferences in a second-language multimedia learning environment. Journal of Educational Psychology, 90(1), 25-36.

Plass, J. L., Chun, D. M., Mayer, R. E., \& Leutner, D. (2003). Cognitive load in reading a foreign language text with multimedia aids and the influence of verbal and spatial abilities. Computers in Human Behavior, 19, 221-243.

Richards, J. C., \& Rodgers, T. S. (2001). Approaches and methods in language teaching. New York, NY: Cambridge University Press.

Rost, M. (1990). Listening in language learning. New York, NY: Longman.

Schmidt-Weigand, F., \& Scheiter, K. (2011). The role of spatial description in learning from multimedia. Computers in Human Behavior, 27, 22-28.

Schwamborn, A., Thillmann, H., Opfermann, M., \& Leutner, D. (2011). Cognitive load and instructionally supported learning with provided and learner-centered visualizations. Computers in Human Behavior, 27, 89-93.

Thomas, P. R., \& McKay, J. B. (2010). Cognitive styles and instructional design in university learning. 
Learning and Individual Differences, 20, 197-202.

Vanderplank, R. (1988). The value of teletext subtitles in language learning. ELT Journal, 42(4), 272-281.

Wu, M. L., \& Tu, J. T. (2006). SPSS and statistical application analysis. Taipei: Wu Nan.

Yanguas, I. (2009). Multimedia glosses and their effect on L2 text comprehension and vocabulary learning. Language Learning and Technology, 13(2), 48-67.

Yoshii, M., \& Flaitz, J. (2002). Second language incidental vocabulary retention: The effect of text and picture annotation types. CALICO Journal, 20(1), 33-58.

Corresponding author: Hui-Yu Yang, yangh936@163.com

Australasian Journal of Educational Technology (C) 2014.

Please cite as: Yang, H-Y. (2014). Does multimedia support individual differences? - EFL learners' listening comprehension and cognitive load. Australasian Journal of Educational Technology, 30(6), 699-713. 